\title{
Ideario lingüístico en la enseñanza del latín durante los siglos XVII y XVIII. La pugna entre lenguas vernáculas: el Nou mètode per aprendre la llengua llatina de Antoni Portella
}

\section{Language Ideas in the Teaching of Latin in the 17th and 18th Centuries. Rivalry between Vernacular Languages: Antoni Portella's Nou mètode per aprendre la llengua llatina}

\section{Rosa Calafat Vila}

Instituto de Estudios Hispánicos en la Modernidad (IEHM).

Universidad de les Illes Balears (UIB)

ESPAÑA

rosa.calafat@uib.cat

[Hipogrifo, (issn: 2328-1308), 5.2, 2017, pp. 357-379]

Recibido: 12-01-2017 / Aceptado: 06-03-2017

DOI: http://dx.doi.org/10.13035/H.2017.05.02.21

Resumen. Antoni Portella i Enric presentó al Ayuntamiento de Palma en 1764 su obra titulada Nou mètode per aprendre la llengua llatina. Primera part dels Rudiments, exponente claro de los dictados de Port-Royal y del ideario pedagógico renovado, en boga desde el siglo XVII. La obra, que se venía usando con éxito en las escuelas menorquinas, no cuajó en el contexto mallorquín. El hecho de estar escrita en catalán, idioma que discurría con normalidad en la Isla menor sujeta al Tratado de Utrecht, y a la vez entrar en competencia con versiones y gramáticas de 
los expertos que juzgaron su idoneidad, la sitúa en el punto de mira de un debate sobre la metodología de la enseñanza del latín semejante a los que se vivieron en Europa entre los siglos XVII y XVIII, con el valor añadido de la pugna entre las dos lenguas vulgares, catalán y castellano. Este trabajo da a conocer la controversia de ideas que entorno a las lenguas catalana, castellana y latina se vivió en la segunda mitad del siglo XVIII en Mallorca y Menorca en el ámbito de la educación; así como, las obras gramaticales en uso.

Palabras clave. Gramática latina; lenguas vernáculas; siglos XVII-XVIII; enseñanza; contexto cultural y social; Mallorca y Menorca en el siglo XVIII; Nou mètode; debate lingüístico.

Abstract. In 1764, Antoni Portella i Enric presented his book titled Nou methode per aprendre la llengua llatina. Primera part dels Rudiments (in English: A new method for learning Latin. Part one of the rudiments) to the Palma Town Hall. The book exemplified Port-Royal dictates and the fashionable educational ideas of the 17th century; it was successfully used in Minorcan schools, but it did not catch on in Majorca. The fact that it was written in Catalan, a language that was commonly used on the smaller island subject to the Treaty of Utrecht, and competed with grammar books created by experts who questioned its adequacy, put it at the center of a debate on the methodology for teaching Latin, as was common across Europe in the 17th and 18th centuries, but with the addition of the conflict between the two vernacular languages, Catalan and Spanish. This work deals with the controversy of ideas about the Catalan, Spanish and Latin languages that was lived in the second half of the eighteenth century in Mallorca and Menorca in the field of education; as well as the grammatical works in use.

Keywords. Latin Grammar; Vernacular Languages; 17th Century; 18th Century; Teaching; Sociocultural Context; 18th Century Majorca and Minorca; Nou mètode; Linguistic Debate.

\section{INTRODUCCIÓN}

En el año 1762, Antoni Portella i Enric publica en Menorca el Nou methodo per apendre la llengua llatina. Primera part dels Rudiments², durante la ocupación francesa de la Isla. Su gramática sigue los nuevos dictados pedagógicos de PortRoyal, liderada por los maestros Arnauld y Lancelot, autor este último de la obra Nouvelle Méthode pour apprendre facilement et en peu de temps la langue latine, editada en 1644, en cuyo prólogo se da a conocer el ideario de la escuela francesa, de la que es deudor, en título y contenido, el método del menorquín. El autor pretende en 1764 introducir su obra en la isla de Mallorca, gobernada por leyes

1. El autor firma Antoni Portella Anrich, al que normalizando la grafía, según los criterios adoptados por la Gran Enciclopèdia Catalana, citaremos como Antoni Portella i Enric.

2. En adelante citado como Nou mètode. A partir de ahora regularizamos la ortografía de acuerdo con las normas del catalán actual en las citas en lengua catalana. Del mismo modo, procederemos con las del español. 
borbónicas que se esforzaban en hacer del castellano la lengua universal. Las aspiraciones del menorquín toparán con una administración que debe rendir cuentas al Consejo de Castilla y con unos expertos que primarán sus intereses particulares y la fidelidad al statu quo político sobre la idoneidad del método en sí.

La importancia de las lenguas romance, la claridad y la sencillez serán los pilares sobre los que se asentarán los maestros portroyalistas del siglo XVII, que pretenden así superar el tradicional y normativizado modelo jesuítico ${ }^{3}$. La nitidez expositiva, la estructuración simplificada, los textos clásicos que se traducirán del latín al francés y no viceversa, la comprensión textual y la memorización de la regla simplificada a partir de la rima, cuyo estudio debe permitir el avance hacia la comprensión de reglas más complicadas, conformarán el dogma de estos gramáticos. Para ello, la presencia de la lengua vernácula será imprescindible. Al igual que los de Port-Royal, Portella entenderá su obra como un peldaño más en la consecución de conocimientos más arduos: "Y si estos Rudiments tenen acceptació en esta Isla, donaré a llum la segona part de este nou mètode, qui contindrà las partícules i les regles més dificultoses de la sintaxis» ${ }^{4}$. En la Europa del Setecientos, maestros y obras caminan hacia una enseñanza contextualizada que responda a la edad y al entorno del alumno. Johann Amos Comenius, pedagogo checo autor en 1632 de la Didactica Magna, reflexiona sobre la manera de optimizar el aprendizaje del latín sugiriendo que «las palabras jamás debían aprenderse separadas de las cosas» ya «que no convenía comenzar el estudio de una lengua por su gramática, sino con frases sencillas y objetos corrientes para después ir ascendiendo hasta las frases más complicadas y los objetos menos usuales» ${ }^{5}$. La renovación pedagógica se abastecerá de las ideas científicas de la época, L'Encyclopédie va a significar el enriquecimiento de la lengua a través de las adquisiciones científicas ${ }^{6}$. Los maestros de Port-Royal ${ }^{7}$ aplicarán el método científico de Galileo, Bacon o Descartes a la enseñanza de la lengua ${ }^{8}$. Siguiendo a Descartes, concebirán «la gramática general como subyacente a la constitución real de todas las lenguas» ${ }^{9}$; y adecuándose a los dictados políticos y lingüísticos del entorno apostarán por la lengua del nuevo Estado: «como patriotas eruditos se enorgullecían en la claridad, elegancia y belleza que veían en la lengua francesa, un testimonio del cambio en las actitudes de los

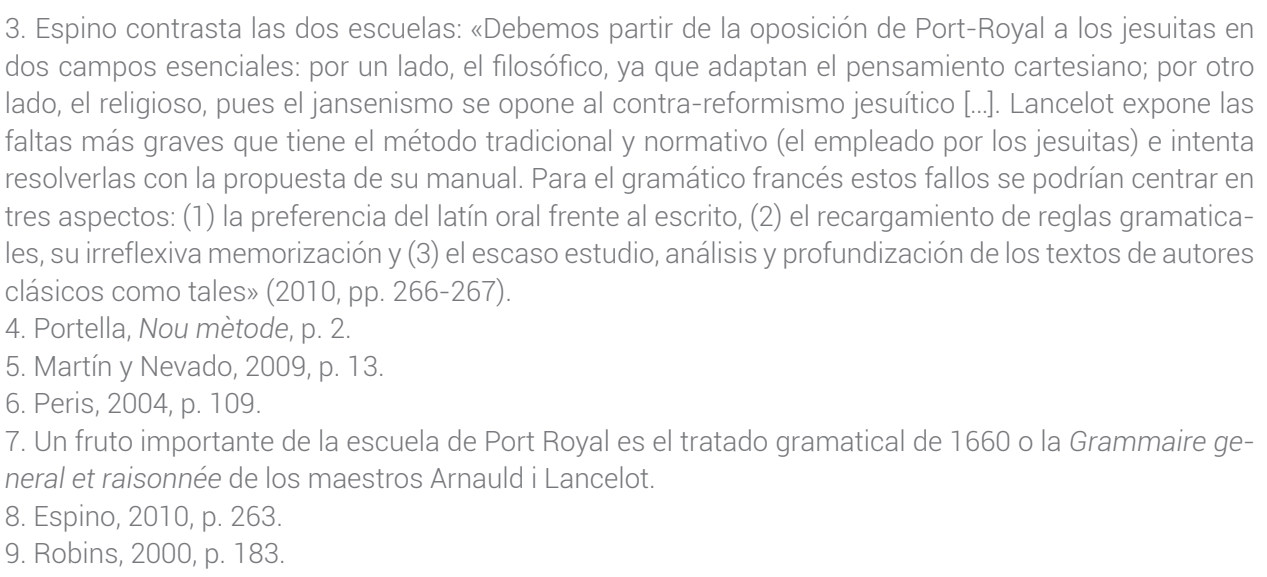


hombres hacia las lenguas vernáculas europeas que había forjado el Renacimiento» ${ }^{10}$. Este es el sentir de los intelectuales del siglo XVII que, con su proceder, van a contribuir a desproveer a la lengua clásica de su vitalidad social, que no cultural: «Toda lengua, aunque sea de las muertas se aprende más por el uso que por las reglas» ${ }^{11}$, dirá nuestro gramático. Para Portella, al igual que para sus maestros franceses, la lengua vulgar se convertirá en materia por sí misma e instrumento de acceso a todo conocimiento. Así lo manifiesta el padre Miquel Abrines, en el informe que prepara para el Ayuntamiento de Palma sobre el Nou mètode, destacando la necesidad de gramáticas que se dirijan a los estudiantes en su lengua materna y se alejen de métodos "antiguos" como el del Sempere ${ }^{12}$, «medio intolerables» para los muchachos: «como lo sería si para aprehender otros idiomas más fáciles, como son el italiano, francés, etc. se diesen las reglas en cada una de estas respectivas lenguas» ${ }^{13}$.

El gramático recoge en el prólogo de su Nou mètode las doctrinas portroyalistas, a imitación del Nouvelle Méthode de Lancelot. Su obra se asienta en dos principios básicos: la simplicidad de preceptos y el uso de la lengua vernácula del alumno, el catalán: «Los Reines més instruïts de la Europa [...] formaren Rudiments de la Grammatica llatina en llengua materna [...], amb un mètode molt clar, i proporcionat als principiants» ${ }^{14}$. En su defensa ${ }^{15}$ alega ante el Ayuntamiento palmesano, el 11 de mayo de 1764, que recurre a la práctica europea como cita de autoridad: «Yo en esto no voy por mi capricho, tengo muchos autores cuyos métodos han sido aplaudidos de todo el orbe» ${ }^{16}$. Con mayor o menor acierto, presenta un trabajo que responde a las premisas de sencillez expositiva y uso de la lengua vulgar, a manera de las de los renovadores de los siglos XVII y XVIII: «reglas debe tener», dirá, en la estela de la preceptiva neoclásica y en defensa de su ideario pedagógico; y replicando a las duras argumentaciones de sus críticos, que abogan por seguir con los métodos más tradicionales, añadirá: «pero no tantas que al fin de diez o doce meses no se haya desembarazado el niño de ellas, ni de tan corto número que en ocho días se halle fuera de ella. Esto respondo, en cuanto parece faltan a mi método muchas reglas y excepciones» ${ }^{17}$.

\footnotetext{
10. Robins, 2000, p. 183.

11. Calafat, 1993, p. 629

12. Andreu Sentpere, transcrito siguiendo el criterio normativo de la Gran Enciclopèdia Catalana, estudia medicina en Valencia, donde ejerce de catedrático de gramática y retórica a partir de 1539. Su Grammaticae latinae institutio (1546), conocida como el «Sempere» o el «Semperi», a pesar de rivalizar con la gramática de Nebrija, gozó de mucha vitalidad; siendo reeditada más de cuarenta veces hasta el siglo XIX, de las cuales treinta se hicieron en Mallorca.

13. Calafat, 1993, pp. 618-619. Informe del padre Miquel Abrines del convento de la Merced de Palma resaltando las cualidades del Nou mètode.

14. Portella, Nou mètode, p. 2.

15.Papeles de varios asuntos de la Ciudad de 1762 a 1764, Archivo Municipal del Ayuntamiento de Palma, en Calafat, 1993, pp. 589-634. La documentación citada se recoge en la tesis doctoral titulada Llengua i repressió a la Malloca del segle XVIII, parcialmente publicada en 1999.

16. Calafat, 1993, p. 628

17. Calafat, 1993, p. 629
} 
La polémica que en 1764 genera, entre los especialistas escogidos por la corporación municipal, la idoneidad de la gramática de Antoni Portella refleja parcialmente el conflicto que en Francia se denominó la querelle des anciens et des moderns o lo que en Inglaterra Jonathan Swift en 1704 plasma en su obra The Battle between the Ancient and Modern Books in St James' Library. La peculiaridad e interés del Nou mètode estriba en que la lengua vernácula a la que recurre el autor entra en conflicto con el uso universal de las lenguas nacionales por entonces en auge, lo que convierte la obra y el debate sobre su posible implantación en un filón de argumentaciones pedagógicas y lingüísticas entorno a la enseñanza del latín en la Mallorca del siglo XVIII.

\section{LAS LENGUAS VERNÁCULAS EN LA EUROPA MODERNA. LA ENSEÑANZA DEL LATÍN Y EL CONTACTO LINGÜÍSTICO EN LOS TERRITORIOS DE HABLA CATALANA}

A lo largo del siglo XVI, se asiste a un cambio lingüístico ${ }^{18}$ que supone la transformación del humanismo en latín ${ }^{19}$ al humanismo en lengua vulgar. Dicho fenómeno ocupa buena parte de la historia lingüística de la Europa moderna ${ }^{20}$, resolviéndose a favor de las lenguas consideradas de Estado ${ }^{21}$ :

A partir del comienzo del reinado del Luis XIV (en 1661), el capital acumulado es tan importante, es tan firme la creencia en el poder de esta lengua, que se empieza a celebrar su victoria sobre el latín y su triunfo en Europa. Louis Le Laboureur publica aún en 1667 un tratado titulado Des avantages de la langue françoise sur la langue latin, como si todavía hiciese falta afirmar la supremacía del francés. Pero en 1671 aparecen los Entretiens d'Ariste et d'Eugène, del padre Bohours, que celebran la superioridad del francés sobre todas las demás lenguas modernas pero también sobre el latín 22 .

Europa, entre el siglo XVI y el siglo XVIII, vive un conformismo linguistico nazional unitario ${ }^{23}$, que dará lugar a gramáticas que fijarán el bon usage ${ }^{24} \mathrm{O}$ la acep-

18. Badia, 1995, p. 170.

19. Breva-Claramonte, 1994, estudia el debate que sobre la enseñanza del latín y su optimización tuvieron los autores del Renacimiento, cuyas propuestas recogen los neohumanistas del siglo XVIII.

20. Batllori, 1979, pp. 129-154.

21. Siguiendo los dictados políticos y sociales de la época, los de Port-Royal van a substituir los teoremas de Euclides por los Nouveaux élements de géométrie déduits en francés.

22. Casanova, 2001, p. 94.

23. Danielle Trudeau en su libro Les inventeurs du bon usage sitúa entre 1529 y 1647 el período de construcción de las normas gramaticales y léxicas del francés.

24. La voluntad de imponer el precepto y la norma en catalán se refleja en las Regles de esquivar vocables o mots grossers o pagesívols, de 1492, escritas por el humanista Pere Miquel Carbonell. Esa misma voluntad es la que se desprende de la primera gramática castellana o española, también de 1492. Nebrija la había concebido para facilitar el aprendizaje del latín, aunque «no dejó de presentir que, redactada en castellano, su gramática también podría aplicarse a divulgar el conocimiento de esta lengua» (Badia, 1995, p. 170). 
tación de la Norma en los vulgares ${ }^{25}$. A su vez, dicha normativización permitirá la transformación, refrendada por la autoridad política, de los vernáculos en lenguas universales de uso común, arrinconando la lengua clásica ${ }^{26}$. En pleno siglo XVI la Universidad castellana de Salamanca se esforzaba por mantener el dominio del latín como lengua vehicular ${ }^{27}$. Por su parte, en los colegios universitarios de Girona y de Tarragona se prohibía hablar catalán en las aulas de gramática ${ }^{28}$ con el afán de preservar el uso del latín. La introducción de la lengua corriente en la enseñanza podría deberse, como explica Serra Ràfols para el caso catalán, a una progresiva ruralización de los centros universitarios, que ya eran innumerables en este siglo ${ }^{29}$. Progresivamente, el latín competirá cada vez más con las lenguas vernáculas en expansión ${ }^{30}$, que evolucionarán de mero recurso para la enseñanza las Introducciones de Nebrija, en la edición de 1508 en Barcelona, introducen el catalán en algunos ejemplos y en el vocabulario ${ }^{31}$ a tener la hegemonía absoluta ${ }^{32}$. De este modo se llega a un siglo, el XVIII, que lejos de resistirse a la hegemonía de las lenguas vulgares las va a convertir en lenguas nacionales: «Entre 1700 i 1850, a Europa la llengua esdevé alguna cosa més que un simple mode de comunicació; esdevé un problema, i un problema d'estat» ${ }^{33}$. En 1724 Charles Rollin en su Traité des études argumenta la necesidad de enseñar en francés. Las lenguas se universalizarán, implementándose en todos los ámbitos posibles por ser materia patria. En 1749 el pedagogo catalán Baldiri Reixac publica las Instruccions per l'ensenyança de minyons, primera manifestación en Cataluña de las repercusiones de Port-Royal: «Entre totes les llengües, la que amb més perfecció deuen saber los minyons és la

\section{Nadal, 1999, p. 32.}

26. Ijsewijn, 1996, pp. 191-209

27. González de la Calle, 1916.

28. El latinista valenciano, formado en la universidad de Bolonia, Jeroni Joan Burgues, publica en 1586 y en 1587 en Barcelona y Tarragona respectivamente dos tratados gramaticales que contienen fragmentos en catalán: el Initium sapientiae timor Domini y el Initium sapientiae timor Domini. Praeparatio puerilis ante syntaxim audiendam, ver Solà, 1979.

29. Serra Ràfols, 1970, p. 22.

30. A propósito de las gramáticas proverbiandi y su uso incluso durante todo el siglo XVI, ver Calvo, 2003, pp. 239-254. El autor hace hincapié en el hecho de que las gramáticas latinas con frases en lengua romance cuajaron en la península Ibérica, afirmando que: «las gramáticas de esta serie con notas en romance castellano, catalán, aragonés y valenciano constituyen una síntesis de muchas de las fórmulas pedagógicas empleadas hasta entonces» (p. 240).

31. Marcet y Solà, 1998, p. 53.

32. Nadal, 1992, p. 160, a propósito de la creación de los estados modernos en la nueva Europa subraya el papel fundamental que juegan las lenguas vernáculas: «A la fi del segle XV la civilització llatina unitària de l'occident medieval va començar a transformar-se en el sistema de les llengües nacionals de la nova Europa. Aquesta transformació acompanyava, afavorint-lo, un procés fonamental: I'aparició, en substitució de l'imperi, dels Estats moderns. Crec que és aquí, en la combinació de les transformacions política i lingüística, on cal veure el gran canvi. Les llengües d'Europa, totes, començaven a ésser reivindicades com a llengües nacionals. Per això el moviment de reivindicació nacional, entre altres coses, promogut pel txec Jan Hus es lliga directament amb la primera ortografia de la llengua txeca».

33. Rafanell, 1999, p. 92. 
\|lengua pròpia de sa pàtria» ${ }^{34}$. Los nuevos estados convertirán las recomendaciones pedagógicas en decretos lingüísticos impositivos con afán homogeneizador. La Real Cédula de 23 de junio de 1768, que Carlos III firma en Aranjuez, en su artículo VII manda «que la enseñanza de primeras letras, latinidad y retórica se haga en lengua castellana generalmente donde quiere que no se practique», con el fin de «extender el idioma general de la nación para su mayor armonía y enlace recíproco». El Rapport et projet de décret sur l'organisation générale de l'instruction publique que Concordet presenta en 1792 a la Asamblea Nacional francesa establece que en todos los institutos las ciencias y las letras se enseñarán en francés ${ }^{35}$.

Los eruditos catalanes van a estar al frente de las novedades pedagógicas: «No debe obviarse el hecho de que una de las primeras gramáticas españolas que recibieron la influencia de Port-Royal sea catalana, ya que esta región de España siempre recibió la impronta europea mucho antes» ${ }^{36}$. En 1676, Marcillo, profesor de la Universidad de Barcelona, publica el Arte de Nebrija citando a Lancelot: «La característica fundamental de esta obra estriba en que su autor aclara todas las reglas de Nebrija por medio de una traducción literaria al catalán y otra libre, en la que recoge y explica el sentido de las reglas formuladas en latín por Nebrija» ${ }^{37}$. Aunque la lengua catalana participe del triunfo de las lenguas nacionales sobre el latín, la pérdida de poder político y los acontecimientos históricos la sumen en un escenario de conflicto lingüístico que le impedirá convertirse en lengua universal o de uso exclusivo en su territorio, como sí lo harán las demás lenguas de Estado. De hecho, el método del menorquín no conseguirá el beneplácito de las autoridades por hacer uso de una lengua no aprobada por el Consejo de Castilla, y, por ende, ser un libro no «muy decoroso a la nación española». Así lo expresaban los gramáticos Andreu Sitjar y Bartomeu Sitjar, en su informe sobre el Nou mètode.

Hasta aquí su Majestad, que Dios guarde, y constando cual sea su voluntad en lo tocante a las escuelas públicas de esta Isla, esperamos que Vuestra Señoría Muy llustre mantendrá en su fuerza dicho Decreto, particularmente enseñando dicho don Antonio Portella, presbítero, un método al parecer no aprobado del Real Consejo para las escuelas públicas, y no muy decoroso a la nación española. No necesitando ella de métodos extranjeros por tener muchas y tan bellas gramáticas latinas que han dado la regla a las demás de la Europa ${ }^{38}$.

A partir del 1412 con el Compromiso de Caspe ${ }^{39}$, que supone la entronización de la dinastía de los Trastámara en la Corona Catalanoaragonesa, el catalán inicia un contacto «lento, pero directo y siempre creciente» ${ }^{40}$ con el castellano. Esta situ-

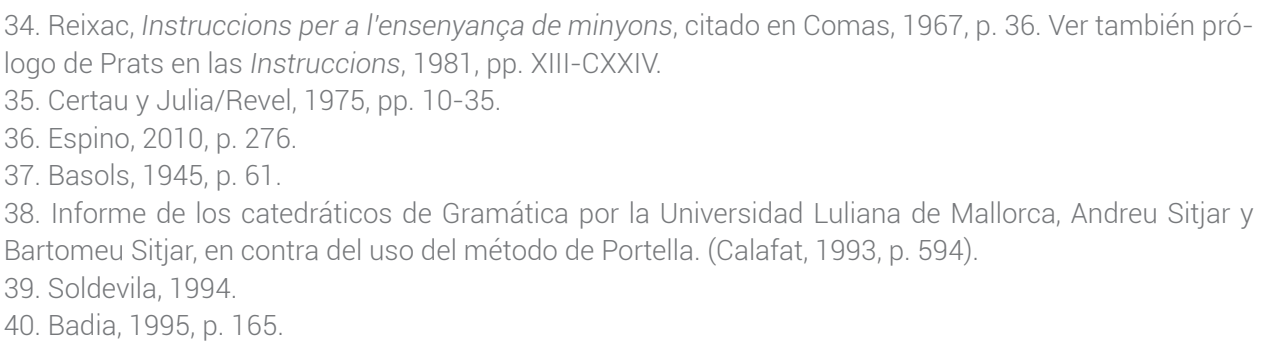


ación de contacto entre lenguas supondrá para el catalán un retroceso en los ámbitos de la cultura áulica: «Mentre Espanya i França tenen poder polític per portar a terme l'estandardització de la LLENGUA nacional -amb gran afany codificador-; a Itàlia aquesta preocupació per la norma s'ha de vehicular a través del autors clàssics. Tant Itàlia com els Països Catalans viuen sense poder polític» ${ }^{41}$. Desde el inicio del siglo XVI, y por razones de Estado, el catalán pasa de una situación de plenitud literaria y territorial «receptor tempranero del humanismo precoz del siglo XIV y propulsor generoso del humanismo maduro del siglo $X V{ }^{42}$ a una subordinación política $^{43}$, que le impedirá formar parte del debate de renovación lingüística que viven las lenguas de Europa. A diferencia de lo que ocurre en el resto del continente, en que las lenguas europeas llevan a cabo su fijación gramatical y modernización, la lengua catalana no llegará a debatir seriamente sobre la "cuestión de la lengua nacional": «L'única gramàtica que es fa dir "catalana", la Gramàtica catalana breu i clara de Llorenç Cendrós (1676), no és més que un manual d'aprenentatge del llati» ${ }^{44}$. Mientras tanto la lengua castellana ve aumentar su prestigio: Carlos V pronuncia un discurso en español en 1536 delante del papa Paulo III y de toda Europa ${ }^{45}$.

Los eruditos catalanes ante este panorama de desconfianza en su propia lengua ${ }^{46}$, se verán obligados a optar por una de las tres vías posibles: fidelizarse al latín, ceder al uso de la lengua castellana en auge, o seguir escribiendo en su lengua propia ${ }^{47}$. De todas ellas, la segunda opción será la que tendrá más adeptos. Cabe decir que el panorama literario y exclusivo de una minoría coincidirá muy poco con la vitalidad y la normalidad que sigue teniendo el catalán en el resto de manifestaciones lingüísticas ${ }^{48}$. En palabras de Benet Girgós, traductor al catalán de un libro de Martín de Ayala de 1579: «Encara que la llengua castellana per tan familiar en nostra província i molts pensen entendre-la i parlar-la bé, totavia no passa així sinó on hi ha concurs i pràctica amb gent d'aquella nació [...]. Fora d'aquest nombre, molt major és el d'aquells qui poc la entenen $»^{49}$. Una prueba de la normalidad del catalán sería la que un siglo y medio más tarde nos procura el pedagogo Baldiri Reixac en sus Instruccions, obra que contó con siete ediciones, además de traducciones al francés y al castellano. El maestro de Girona abogaba por el uso del catalán como idioma patrio; a la vez que incluye al final del libro un diccionario catalán-castellano para que todos los niños pudieran «entendre i parlar la llengua española, que los és

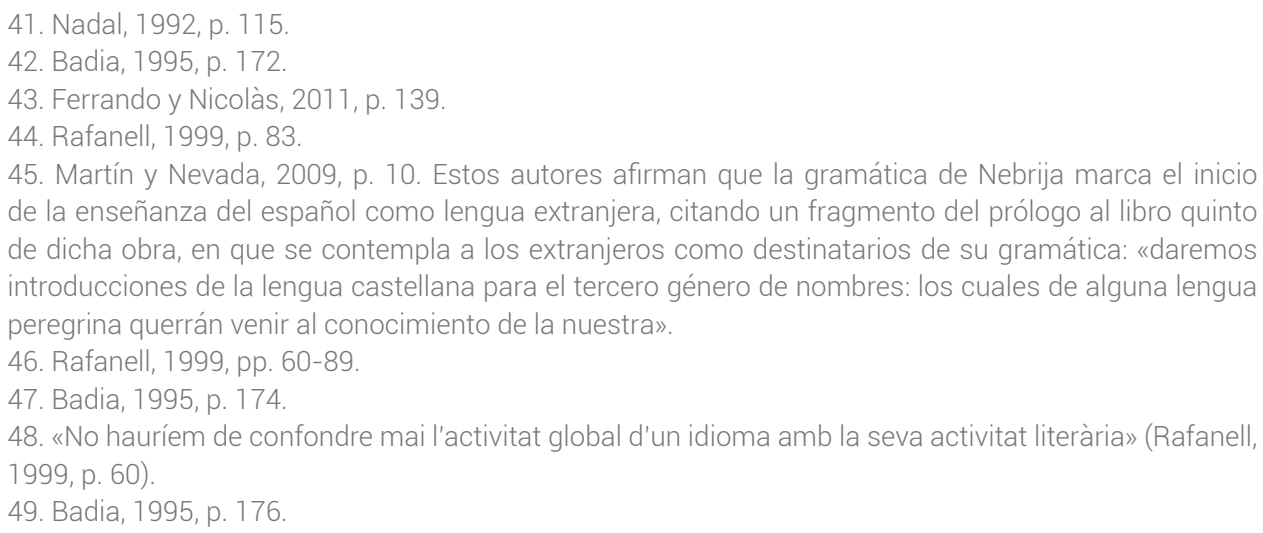


la més útil i necessària de totes les $\|$ engües estrangeres ${ }^{50}$. Acorde con Reixac, y atendiendo a la realidad política del momento, el gramático menorquín en la petición que en 1764 eleva al Ayuntamiento de Palma para que el consistorio promueva el Nou mètode, sugiere la inclusión de un «Diccionario de Principiantes castellano y latino, y viceversa» ${ }^{51}$.

Siguiendo la tradición catalana, Antoni Portella se acogerá a los conceptos de renovación y europeización al defender pedagógicamente la idoneidad de su obra. Alineándose con los preceptos de la escuela francesa, apuesta por una enseñanza deductiva y aboga por el trabajo textual como acto comunicativo, vivo y real ${ }^{52}$. Autores como Locke, Pestalozzi ${ }^{53}$ o Herbart coincidirán en el hecho de que «la lengua que se está estudiando debe hacerse de forma conversada y natural $\rangle^{54}$, aunque esta sea considerada una lengua muerta, como defiende el menorquín. Fiel al ideario expuesto por Reixac y por el resto de maestros europeos, enseña en la lengua natural del territorio: «perquè com podrà un jove principiant entendre unes regles escrites en un idioma, qui li és totalment estrany: esto vertaderament es ensenyar una cosa no coneguda, per medi de altra igualment ignorada» ${ }^{55}$, y ejemplifica a partir de situaciones reales, incluyendo experiencias propias como la ciudad de Toulouse donde se graduó: «El teu Pare morí a las quatre, Pater tuus mortuus est hora quarta. La Iglesia dista de la plaça deu passes, Ecclesia distat à foro decem passibus. Tu estudiaràs dues horas, studebis duabus horis. [...] Tu aniràs aTolosa: ibis Tolosam. Jo partiré per Espanya: proficiscar in Hispaniam» ${ }^{56}$.

La adscripción de los maestros de gramática de la Corona Catalanoaragonesa a los métodos que usaban el catalán para acceder con más facilidad al conocimiento del latín es una de las razones que Gregori Mayans aduce para explicar la poca acogida que su obra tuvo en los territorios catalanes. En el año 1772, se ordena a la Universidad Luliana de Mallorca que adopte la Gramática de Mayans a lo que se niega su Rector, aduciendo que se trata de un método complejo e ininteligible a los alumnos ${ }^{57}$.

A pesar de que el Consejo de Castilla dio hasta tres órdenes para que en las universidades de la Corona de Aragón se leyera la Gramática latina de Mayáns, éstas no fueron cumplidas. Mayáns mismo habla de causas nacionalistas y económicas: «los mallorquines representaron por querer continuar con la Gramática de Andrés Semper escrita en mallorquín. Los catalanes por no dejar la enseñanza de su lengua» ${ }^{58}$.

50. Comas, 1967, p. 40.

51. Calafat, 1993, p. 591

52. En terminología actual, nos referiríamos a los postulados de la Pragmática textual.

53. Menorca contará con una escuela que seguirá el sistema de Pestalozzi. El profesor Cook, refugiado

en la isla menor durante las guerras napoleónicas, fue discípulo del gran pedagogo suizo.

54. Martín y Nevado, 2009, p. 17.

55. Portella, Nou mètode, p. 2.

56. Portella, Nou mètode, pp. 40 y 46.

57. Calafat, 1963, p. 159

58. Sánchez, 2012, p. 463. 


\section{EL AUTOR Y SU OBRA. LAS ISLAS DE MALLORCA Y MENORCA EN EL SIGLO XVIII: CON- TEXTO POLÍTICO Y CULTURAL}

Antoni Portella, natural de Mahón, doctor en Teología por la Universidad de Toulouse ${ }^{59}$, beneficiado de la Catedral de Ciutadella de Menorca y posteriormente capellán del Hospital Militar de Palma, donde fallece en 1765, se dirige un año antes de su muerte al Ayuntamiento de Palma con el fin de que se le concedan tres peticiones: la primera, sustituir al Reverendo Bartomeu Sitjar, uno de los informantes, como maestro de Gramática en el Colegio de la Sapiencia: «Hallándose el Reverendo Bartolomé Sitjar, presbítero, maestro de gramática en el Colegio de la Sapiencia enfermizo, de manera que no puede con la exactitud necesaria acudir al cumplimiento de su cargo...»; la segunda, implantar el Nou mètode en dicho Colegio: «Suplica a vuestra Señoría Muy Ilustre sea de su agrado conceder al suplicante el permiso para pasar a enseñar e introducir en las escuelas de dicho Colegio de la Sapiencia su nuevo método»60; y la tercera, «proteger y promover este muevo método de aprender la lengua latina, evidenciada su utilidad; haciendo que la abracen las escuelas que son del Patronato de Vuestra Señoría para la promoción de las buenas letras $»^{61}$. A cambio, el autor dice ofrecer un método que responde a las exigencias pedagógicas de «las partes más instruidas de la Europa, como Italia, Alemania, etc.»; al tiempo que se compromete a defender su obra delante de «los sujetos hábiles en latinidad y bellas letras que Vuestra Señoría tenga a bien nombrar» ${ }^{62}$.

Por lo que se refiere al contexto social y cultural de nuestro autor, Antoni Portella, como muchos otros que tuvieron que optar por la opción académica como vía de ascenso social yendo a estudiar a Francia a causa de la situación política que vive la isla de Menorca ${ }^{63}$ en el siglo XVIII, estudia en Mallorca, Barcelona y se gradúa en Francia. Los menorquines se doctoraban en Aviñón o Montpelier como teólogos, médicos, farmacéuticos o abogados. Estos profesionales, retornando a su Isla, crearían la Sociedad Mahonesa de Cultura, un núcleo ilustrado que hará de la lengua catalana su medio de expresión ${ }^{64}$ e internacionalización, traduciendo al catalán a Young, Addison, Voltaire y otros muchos.

La redacción del Nou mètode coincide con el período de ocupación francesa de Menorca, entre 1756 y 1763. La obra de Portella aúna dos preceptos: uno general, la nueva pedagogía que emana de Francia; y otro particular, el prestigio que el catalán tenía para los ilustrados menorquines del momento ${ }^{65}$. Las escuelas de la isla menor usarán el método de Portella hasta bien entrado el siglo XIX, aunque a partir de 1802 Menorca pase a manos del rey Carlos III. La imposición del español, que

59. Ferté, 1998, p. 193.

60. Calafat, 1993, p. 590

61. Calafat, 1993, p. 592

62. Calafat, 1993, p. 591

63. Por el Tratado de Utrecht la Isla queda a manos de la reina de Inglaterra. Entre 1755 y 1763 con motivo de la Guerra de los Siete Años fue ocupada episódicamente por los franceses y retornada el 1763. El 1802 por el Tratado de Amiens pasa a formar parte del imperio de Carlos III.

64. Citado por Murillo, 1982, pp. 71-81.

65. Portella, Nou mètode, p. 2. 
había experimentado su extensión legal en Valencia, Mallorca y Cataluña a través de los Decretos de Nueva Planta, entre 1707 y 1716, no se vive en Menorca con la misma intensidad e insistencia; cabe señalar que la Isla no tuvo Nueva Planta de gobierno. El 18 de agosto de 1802, Joan Miquel de Vives i Feliu, capitán general de Mallorca, asume la responsabilidad de implantar las leyes borbónicas en la isla menor, firmando un documento en que se recuerda, de manera laxa, la obligatoriedad del español en la enseñanza:

No es de mi aprobación el que en las escuelas de primeras letras se enseñe a leer en menorquín por estar mandado por S.M. que en todas ellas deba enseñarse en español por ser Idioma General de la Nación, y así se ejecuta en Cataluña y Mallorca, que es cuanto se me ofrece decir sobre el expresado plan que dejo en la Secretaria de esta Gobernación para cuando quiera arreglar este particular ${ }^{66}$.

Cuando el 1756 el Mariscal Duque de Richelieu conquista la isla a los ingleses, las escuelas inglesas desaparecen y en su lugar se fundan otras que serán dirigidas por profesores franceses. El Gobierno francés se propone implantar métodos de aprendizaje del latín que emulen con destreza a los manuales franceses del momento. De ahí el impulso y la aceptación que se da al método de Portella desde Menorca ${ }^{67}$.

En lo tocante a las ediciones de esta obra, tenemos constancia de una impresión de1761 titulada: Rudiments de la llengua llatina per aprendre fàcilment i en breu temps la construcció comuna, obra que consta de ochenta páginas, reeditada en 1762 bajo el título de Nou mètode per aprendre la llengua llatina dedicat al senyor Comte de Lannion. Primera part dels Rudiments. A expenses de l'autor. Amb permissió dels Superiors; ambas impresas en Mahón por Joseph Payen, editor francés instalado en la Isla desde principios de la dominación ${ }^{68}$. El cronista Joaquim Maria Bover en su obra Biblioteca de escritores baleares, de 1868, informa que estamos ante una misma pieza gramatical en la que la edición de 1762 varía de manera insignificante respecto a la de 1761. El erudito reseña cambios en el título, así como la inclusión de un opúsculo, «dels gèneres dels noms», que ocupa las últimas 24 páginas a modo de diccionario para principiantes: «He format este Methodo o Rudiments, a los quals he ajustat un breu tractat de Gèneros, Declinacions, Preterits i Supins, per suplir la falta de Diccionari de principiants» ${ }^{69}$. Por último, la edición de 1762 contiene una dedicatoria en latín al conde de Lannion, gobernador de Menorca durante la dominación francesa. Figura otra edición de $1783^{70}$ impresa en Mahón en casa del notario Joan Fàbregues, en la que se omite por razones obvias, puesto que Portella muere en 1765, la frase «A expensas del autor». Por otra parte,

66. Murillo, 1982, p. 78.

67. Pomar, 1990, p. 228. Citamos la reedición en catalán del libro que escribió el autor con título: Ensayo Histórico sobre el Desarrollo de la Instrucción Pública en Mallorca, Palma, imprenta Soler, 1904.

68. Paredes, 2005, p. 47.

69. Portella, Nou mètode, p. 2.

70. Esta edición está disponible en línea: <https://books.google.es/books?id=H6dkAAAAc

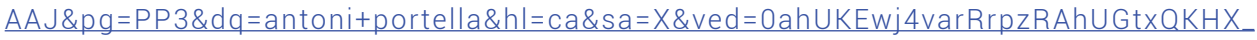
WAiEQ6AEIGTAA\#v=onepage $\& q=$ antoni\%20portella\&f=false $>[30 / 08 / 2017]$. 
Bover, refiriéndose al ilustrado menorquín Joan Ramis i Ramis, explica que «El Dr. Ramis cita una edición de 1760 que no hemos visto» ${ }^{71}$, a la cual se refieren Rafael Oléo, autor de la Historia de la isla de Menorca de 1874, y el erudito mallorquín Joan Pomar i Fuster, catedrático en 1902 de geografía e historia en Mahón. Ambos cronistas resaltan la idoneidad del método de Portella y la controversia que se generó por pretender desbancar al de Sempere.

Algunas reformas quiso introducir en la Isla el Gobierno francés, en el siguiente año de 1762. Considerando este lo poco que adelantaba la juventud, sobre todo en la latinidad con los elementos de Andrés Sempere, los cuales acarreaban sumo trabajo, no tan solo a los estudiantes, sí que también a sus maestros, valiose de los conocimientos y trabajo del Dr. Antoni Portella, el cual había dado a luz en Mahón, en 1760 unos rudimentos de la lengua latina, semejantes á los que estaban en boga en Francia en aquellos tiempos. Mucho adelantaban los jóvenes con semejante método, según opinión de algunos, mientras otros preferían las reglas de Sempere, de modo que divididos así los pareceres, no se logró extinguir del todo el antiguo método, y en Ciudadela prevaleció hasta principios del presente siglo ${ }^{72}$.

El gramático menorquín tuvo que lidiar con métodos consuetudinarios como el Sempere de uso prácticamente exclusivo en Menorca. Lo hizo procediendo a descalificarlo y afearlo, práctica habitual ya entre los eruditos del Renacimiento: «Es lo que hicieron el Brocense y otros gramáticos que se consideraban a sí mismos modernos contra Nebrija» ${ }^{73}$. Los neohumanistas siguieron cultivando dicho hábito con el fin de acabar con ciertos monopolios ${ }^{74}$. Conforme a tal costumbre, el Nou mètode rivaliza con el de Sempere por ser un obstáculo a sus intereses. Antoni Portella, haciendo uso de los argumentos tópicos que los gramáticos del Renacimiento pusieron en boga y que sus contemporáneos supieron rescatar, arremete contra la gramática del valenciano a la que califica de desproporcionada e incompetente: «El poc adelantament en llatinitat, que s'experimenta en la joventut menorquina, qui no és inferior en ingeni a les demés nacions, prové en gran part de la improporció del llibre que s'ensenya en les Escoles de esta Isla» ${ }^{75}$; además de perniciosa, si se compara con la nueva obra: «Los nombres, primer paso para aprender la lengua latina están en tal claridad y facilidad que un muchacho de mediana capacidad en ocho días puede hacerse capaz de ellos, necesitando con el Semperio de más de tres meses» ${ }^{76}$.

Retomando la cuestión de las ediciones, debemos plantearnos la hipótesis de la existencia de otra versión del Nou mètode expresamente elaborada para las escuelas de Mallorca, no necesariamente editada. Nos basamos en los informes que los expertos, nombrados por el consistorio palmesano, elaboraron a propósito

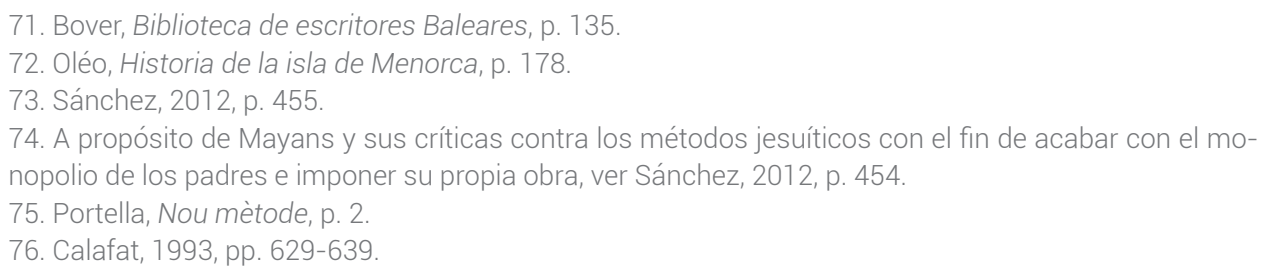


de la obra del menorquín. Tales documentos resaltan errores gramaticales que no constan en la edición de $1762^{77}$. A modo de ejemplo, el informante Antoni Balaguer sonsaca un error que no aparece en la citada edición: «Folio 16 página 1, ffo. Si la partícula, dize: si las partículas "que" vienen después de videor, dicor y fateor, debe decir: y feror porque fateor es verbo deponente agente» ${ }^{78}$. En el texto de 1762 no consta fateor. Además, el autor, en su alegato de defensa, no desmiente la existencia de dichos errores, simplemente los justifica: «Por conclusión, tendré el honor de decir a Vuestra Señoría que en materia de métodos para aprender lenguas, no se hallará ni puede hallarse gramática perfecta. En todas encontraremos que criticar cosas, que corregir y mucho que enmendar» ${ }^{79}$. El padre Abrines, el único que recomienda el uso en Mallorca del Nou mètode, ratifica la existencia de faltas en la obra, a la vez que expresa la voluntad del autor por enmendarlos: «que se introduzca el nuevo método del doctor Portella, corregidos antes los errores de latinidad [...], pues a su corrección, sin la menor repugnancia, se ofreció el dicho doctor» ${ }^{80}$. A favor de la hipótesis formulada, está que Antoni Portella en su alegato ante el Ayuntamiento palmesano nos da a conocer la existencia de un supuesto amanuense al que se le imputan los errores: «por puramente inadvertidos los dejó pasar el amanuense» ${ }^{87}$. A tenor de lo expuesto, bien debía entender el autor la necesidad de introducir cambios que se ajustaran a las exigencias políticas y sociales de la Mallorca del Setecientos, que poco o mucho debían afectar a la obra; como la dedicatoria al conde de Lannion, gobernador de Menorca en nombre del rey de Francia, Luís XV, texto laudatorio sin sentido en tierras del rey Carlos III. El autor, consciente de tener en Mallorca un entorno diferente, se dirige en castellano al Ayuntamiento de Palma y en catalán a las autoridades menorquinas. El 10 de junio de 1761, Portella solicitaba en catalán a sus autoridades el permiso reglamentario para introducir el Nou mètode en Menorca:

És notori que de los minyons qui segueixen les escoles de gramàtica de la llengua llatina, no se encontrarà un qui la posseesca amb la deguda perfecció [.... Este defecte tan notable en moltíssims menorquins no se pot atribuir a altra cosa que a la falta de método en lo ensenyar llatinitat [...]. Per esto, desitjós d'evitar tots aquests perjudicis he determinat donar al públic una gramàtica de llengua menorquina ${ }^{82}$.

Más allá de realidades circunstanciales y elitistas, nuestro gramático, inmerso en el ambiente ilustrado y europeo de la comunidad intelectual menorquina, escribe

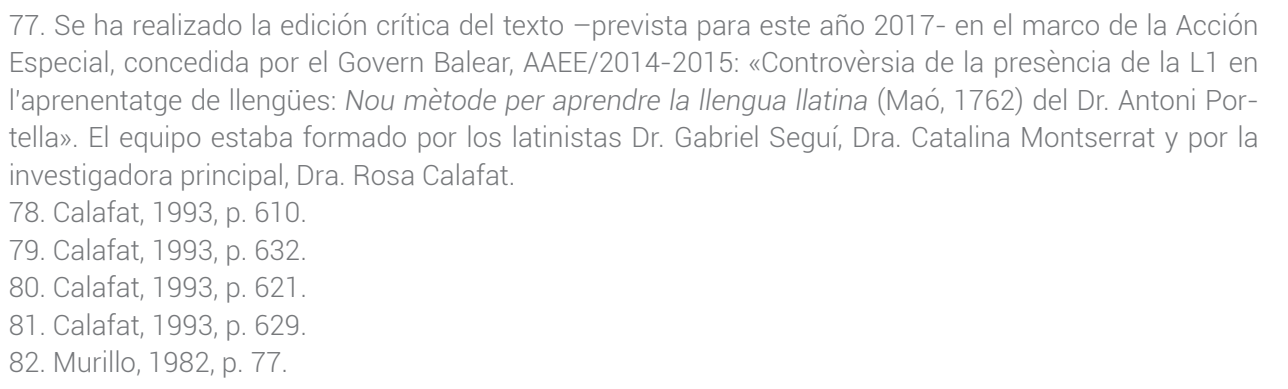


para toda la comunidad catalanohablante, ajustándose a la norma compartida, al bon usage, y enalteciendo lo que él considera su lengua nacional:

\section{DEL NOM SUBSTANTIU}

P. Qual és el nom substantiu?

R. És aquell qui subsisteix per si sol, i se declina per un o dos articles; v. g. hic Dominus; hic, o haec dies.

P. Quantes són les Declinacions del Nom?

R. Cinc, la primera fa el Genitiu Singular en ae, diftongon; v. g. Doctrina, Genitiu Doctrinae; la segona fa el genitiu en $i$ v. g. Templum, Genitiu Templi, la tercera fa el Genitiu en is; [p. 3]. v. g. Auditor, Genitiu Auditoris. La quarta fa el Genitiu en us; v. g. Sensus, Genitiu Sensus. La quinta fa el Genitiu en ei; v. g. dies, Genitiu diei³.

Para los eruditos de la Corona Catalanoaragonesa las denominaciones administrativas de la lengua, como llengua mallorquina o llengua menorquina, no significarán en ningún caso una reducción territorial de la misma. Lo expresa claramente, en 1804, el gramático menorquín Joaquim Pons ${ }^{84}$, autor de los Principis Generals de la Llengua Menorquina:

Jo he intitulat aquesta obra Principis Generals de la Llengua Menorquina no perquè considèrie que aquesta llengua dèguie el seu origen a Menorca, sinó perquè essent feta a Menorca i per un menorquí no és únicament per als menorquins, sinó també per als mallorquins, catalans, valencians, etc. que jo he treballat aquesta gramàtica i no sols perquè ténguien un método per aprendre de parlar i escriure la seva llengua; sinó perquè púguien aprendre més fàcilment les altres llengües vulgars de l'Europa llatina ${ }^{85}$.

\section{LAS GRAMÁTICAS PARA LA ENSEÑANZA DEL LATÍN EN LA ISLA DE MALLORCA: EL NOU MĖTODE}

La Gramática de Antoni Portella fue evaluada por una comisión de ocho expertos, escogidos entre diferentes órdenes religiosas y grados de estudio, preuniversitarios y universitario, que se pronunciaron, entre el 11 y el 19 de mayo de 1764, mayoritariamente en contra ${ }^{86}$. Formaban la Comisión: Miquel Abrines, religioso del convento de la Merced; Francesc Pla y Joan Company, jesuitas del colegio de Montesión; Antoni Balaguer, maestro de Gramática del convento de Sant Francesc; Llo-

83. Portella, Nou mètode, p. 4.

84. El estudioso Jordi Carbonell, en primera instancia, atribuye la obra al ilustrado menorquín, Antoni Febrer i Cardona, primo del que después sería reconocido como el verdadero autor, Joaquim Pons. Ver Murillo, 1982, p. 79

85. Murillo, 1982, pp. 79-80.

86. Los informes que elaboran los expertos están datados entre las fechas señaladas. Contrariamente, las dos solicitudes que dirige Antoni Portella al Consistorio, una con las tres peticiones expuestas y la otra expresando la necesidad de un diccionario de principiantes en castellano y latín y viceversa, solo recogen el año. 
renç Company, maestro de Retórica en el mismo convento; Andreu y Bartomeu Sitjar, catedráticos de Gramática de la Universidad Luliana de Mallorca, y Pere Tomàs Cifre, carmelita, ex catedrático de Retórica de la Universidad Luliana. Los motivos por los que se rechaza el Nou mètode responden, por una parte, a intereses particulares de los miembros de la Comisión, autores algunos de ellos de gramáticas o simplemente de adaptaciones al Sempere y al Nebrija; destacando el caso más flagrante de Bartomeu Sitjar, cuya plaza de maestro del colegio de la Sapiencia ${ }^{87}$ pretendía ocupar el menorquín; quien se dirigía al Ayuntamiento para solicitar «el permiso para pasar a enseñar e introducir en las escuelas de dicho Colegio de la Sapiencia su nuevo método [...]; sin que de tan trabajosa tarea pretenda perjudicar en nada al citado Reverendo Sitjar en el estipendio que le tiene destinado el Muy Ilustre Ayuntamiento» ${ }^{88}$. Por otro lado, desacreditar al autor y a su obra no fue tarea laboriosa para los miembros de la Comisión, les bastó con apelar a la situación política de la Mallorca del momento y arremeter contra el uso del catalán para desestimarla.

Si bien la obra de Portella triunfa en Menorca, no sin competir con la de Sempere, la isla mayor será territorio inexpugnable. El autor deberá enfrentarse a dos colosos: por una parte, a unas leyes borbónicas que prohíben el uso del catalán; y, por otra, a la institucionalización de la obra de Nebrija, método que a finales del siglo XVI se imponía ya, por dictamen de Felipe III, como texto único en las universidades $^{89}$; arrinconando, pese a su triunfo en el resto de Europa ${ }^{90}$, a la Minerva del Brocense; manual que inspirará a los jesuitas reformadores, «dado que el Brocense, que fue prácticamente el mentor de Lancelot, era español, los jesuitas reformistas citados prefirieron dejarse influir por el gramático extremeño y sus seguidores más que por Lancelot y Arnauld $»^{91}$. El apoyo legal que recibe la obra de Nebrija y la pretensión de hacerla universal en las escuelas del Reino, obliga al Ayuntamiento de Palma, ajustándose a los dictados de Carlos III, a encargar, el 26 de agosto de 1768 , al carmelita fray Pere Tomàs Cifre, uno de los informantes del Nou mètode, la revisión «del libro Antonio de Nebrija llamado "Arte Regio"», para que «ponga las notas que le parecieren útiles para la mejor enseñanza de la juventud ${ }^{92}$. En la misma disposición, el consistorio solicita permiso al Real Consejo para llevar a cabo la impresión del nuevo manual, que el 27 de setiembre de aquel año saldría a la luz con el fin de que «la juventud mallorquina» dispusiera de «un método nuevo y muy fácil, una gramática latina arreglada a la Reales Cédulas de la Majestad de

87. El Colegio fue fundado en Palma por el canónigo lulista Bartomeu llull en el año 1633. Acogía a doce aspirantes al sacerdocio, más dos familiares y un cocinero; sus patronos eran el obispo de Mallorca y el ayuntamiento de Palma. En el período de 1773 al 1783, fue clausurado a causa de las ideas antilulistas del que fuera obispo de Mallorca, Juan Díaz de la Guerra, el cual recluyó a Andreu Sitjar, que como gramático de la Universidad Luliana de Mallorca se oponía a los planes del obispo de anexionar el colegio de la Sapiència al Seminario.

88. Calafat, 1993, p. 590

89. Basols, 1945, p. 58.

90. Lázaro Carreter, 1985, pp. 153-154.

91. Espino, 2010, p. 277.

92. Calafat, 1993, p. 646 
Carlos III»93; así lo haría constar el Ayuntamiento palmesano. El carmelita, que en su día ya apostó por la solución adoptada, recibiría por el encargo un sueldo de 30 pesos; mientras que su amanuense, Miquel Puig, se vería obligado a reclamar una remuneración a la institución municipal ${ }^{94}$.

No sorprende que Pere Tomàs Cifre elaborase un informe, a propósito del Nou mètode, defendiendo el uso del Nebrija del padre jesuita Juan Luís de la Cerda, que en 1603 lo moderniza reduciendo reglas y añadiendo «notas explicativas, que contenían doctrina del Brocense»95; a la postre, él pretendía hacer lo mismo. Por ello, aunque recomiende «el epítome sobre el Arte de Nebrija del Padre Juan Luís de la Cerda de la Compañía de Jesús», por ser un método «breve y fácil», que pone «en español las partes de la oración»", se atreve a dar un paso más y a sugerir la elaboración de una nueva versión que supere a la del jesuita: «o si a juicio de hombres muy doctos y experimentados se hallara o inventara otro mejor, este fuese el preferido y abrazado» ${ }^{97}$. El carmelita tan solo deberá esperar cuatro años para que el Ayuntamiento de Palma le haga el encargo a que tanto aspiraba. En el informe, que firma a 19 de mayo de 1764, se atreve a sugerir la idoneidad de un método a «la semejanza de otros métodos aplaudidos por experiencia en varias naciones, esto es, su disposición en lengua vulgar o española ya fácil, y casi ordinaria en Mallorca»98; opinión, esta última, que dista mucho de la realidad descrita por altos funcionarios de su Majestad. El intendente Miguel Bañuelos en la carta que el 1777 envía al Consejo de Castilla recomienda trasladar a la Isla maestros de Castilla para que enseñen la lengua de España; exponiendo que «la gente que se tiene por culta, el mallorquín es su predilecta explicación entre ellos y con nosotros dan mil tropezones [...]. Los demás no hay forma de que hablen una palabra castellana y de aquí se infiere lo que será el pueblo vulgar»»9. La misma pasión en que acomete la defensa de la obra de Nebrija es la que mueve al padre carmelita a rechazar la de Sempere «el que infelizmente padece aún la juventud mallorquina» ${ }^{100}$, y a oponerse al Nou mètode; ambos con presencia y uso del catalán.

No cabe duda que Antoni Portella propone la introducción de su método en un contexto de poder alejado de los cánones ideológicos de la intelectualidad menorquina ilustrada. El mismo autor, reconociendo su situación, se defiende de los evaluadores alegando que «al parecer no tiran sino a afear la persona y no al método» ${ }^{101}$. Aunque la realidad es que atinan contra ambas cosas, método y autor. Así lo pone de manifiesto el franciscano Llorenç Company, que aunque admite no haberse entretenido demasiado en analizar la obra del menorquín, no se refrena en las críticas: «De suerte que por más que me empeñara a excusar a dicho método de

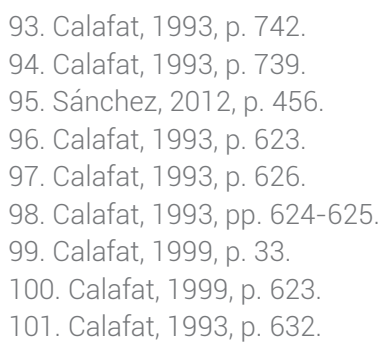


sus faltas, nunca fueran bastantes las excusas. Solamente le excusa el saber que los libros no son capaces de tenerse la culpa»102.

De entre los dictámenes que la comisión elabora, el más extenso es el que firma, el 15 de mayo de 1764, en solitario el catedrático de la Universidad Luliana, Andreu Sitjar, autor de la obra: Nueva gramática para aprender con facilidad la lengua latina. Se trata de un discurso que echa mano de los tópicos para afear el Nou mètode, tachándolo de bárbaro: «No permitan, pues, los cielos por vía alguna salga a luz dicha obra tan precipitada, para que no se ponga a riesgo de perderse la latinidad» ${ }^{103}$. Sitjar, además, arremete contra el uso del catalán: «¿Qué fruto ha sacado dicho Portella en la enseñanza por un año y medio con este método en idioma vulgar? Poca, se ve» ${ }^{104}$. No es que el catedrático esté en contra de la presencia de la lengua vernácula en la enseñanza del latín, él es autor de una gramática en lengua vulgar y él mismo aboga por el método del jesuita portugués, Emanuel Álvarez ${ }^{105}$, muy criticado por Mayans ${ }^{106}$, por acogerse al español: «Vemos que el padre Emanuel Álvarez, que se usa en esta isla, en su prosodia pone su regla en verso latino y después explica aquella con lengua española» ${ }^{107}$. Su objeción no es pues al uso de las lenguas vernáculas sino a la presencia del catalán; como pone de manifiesto en el informe que firma conjuntamente con Bartomeu Sitjar, donde se juzga el método del menorquín de «no muy decoroso a la nación española» por razón del idioma.

La entrada del Nou mètode en Mallorca hubiera supuesto una competencia para los intereses de los informantes, los que o bien tenían su propio método o bien otras creencias que distaban mucho del espíritu pedagógico plasmado en la obra de Portella; a lo que le debemos sumar su pretensión de ocupar la plaza de Bartomeu Sitjar en el colegio de la Sapiencia. Todo ello no contribuía a que la Comisión aplaudiera sus aspiraciones; al fin y al cabo, debían actuar de manera gremial.

El patrón argumental descrito, desmerecer la obra evaluada y rechazar la lengua vulgar con la que se expresa, se evidencia, con leves cambios de matices, en prácticamente todos los componentes de la Comisión. Citamos como ejemplo el caso de Antoni Balaguer, gramático en el convento de Sant Francesc, autor de la obra: Significados de las ocho partes de la oración del primer libro del Dr. en Medicina, D. Andrés Semperio, con dos ortografías latina y castellana, todo muy útil para aprovecharse en la lengua latina y arte de escribir; que sigue las directrices descritas; $y$, consecuentemente, tacha de «inútil, pernicioso, ofensivo a los oídos de los peritos gramáticos y por no hallar en todo el libro cosa digna de la menor alabanza» ${ }^{108}$,

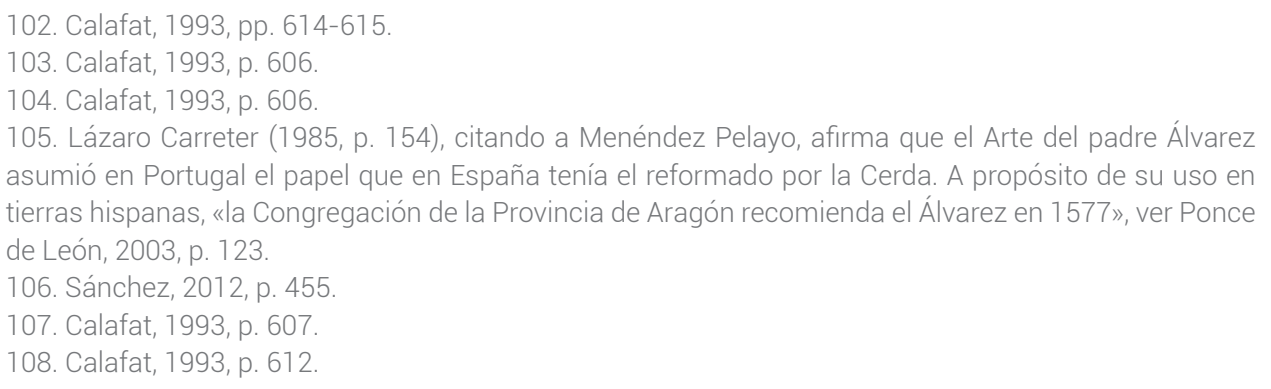


el trabajo del gramático menorquín. Casualmente, Balaguer ${ }^{109}$ aprovecha su dictamen, como lo hiciera el padre Cifre con su Nebrija adaptado, para recomendar al consistorio municipal el uso del Sempere versionado. No resulta difícil suponer que el experto apostaba por su obra, aduciendo que si se considera el "Simperio" arduo y difícil, «se podrá señalar algunos, que no faltan en este Reino de óptimos y peritísimos maestros, para que o quiten al Simperio lo que le hace dificultoso o le añaden algo para hacerle fácil» ${ }^{10}$.

Atendiendo a la práctica unanimidad de la Comisión en lo tocante a razones e intereses particulares, no nos sorprende la similitud que guardan los informes entre sí. Destaca el parecer de Antoni Balaguer y Llorenç Company, maestros del colegio de Sant Francesc de Palma, porque ambos citan al menorquín como Antonio Portell, errando en el apellido, y ambos defienden el uso del Sempere en las escuelas mallorquinas; si bien Company, no viendo la necesidad de un nuevo método, sugiere que se siga la práctica habitual de dar la explicación del Sempere en mallorquín. Puede que la diversidad de parecer venga motivada por el hecho de que Company, a diferencia de Balaguer, no parece tener autoría de ninguna gramática. Recordemos que Company a pesar que reconoce que no ha podido revisar el Nou mètode con rigor «a causa de la prisa con que corre a darle a la pública luz y a hacerle correr; no obstante esto, diré, ingenuamente, lo que siento... ${ }^{111}$, no se contiene en desmerecerlo.

Cuanto a lo que toca a ser fácil el método porque está en nuestro vulgar idioma, me parece más concerniente y más conforme a la facultad de la lengua latina el que se enseñe en latín, o con reglas latinas; que si no lo entienden aún los muchachos, ya se les repite la licción y se les explica en mallorquín en todas las escuelas de Mallorca ${ }^{112}$

Por último citamos a los jesuitas Joan Company ${ }^{113}$ y Francesc Pla, gramáticos del colegio de Montesión, que juzgan la obra de prescindible: «dicho método no es más útil que el que actualmente se sigue en las escuelas»114. Siguiendo la tónica de la Compañía, abogan por el uso del Arte de Nebrija por ser el que ordinariamente se da en España, y por «exacto, fácil y seguro». Reclaman, fieles al ideario de los gramáticos barrocos, que todo ejemplo debe ser «de autor latino del siglo de oro»; por ello, descalifican sobremanera las ejemplificaciones al uso de nuestro autor. A diferencia de los catedráticos de la Universidad Luliana, del carmelita Pere Tomás Cifre y de Balaguer, los maestros jesuitas no parecen rechazar la presencia del catalán en la enseñanza, incluso recomienda que se siga aplicando «un tratadillo

109. Bover, Biblioteca de escritores..., p. 53.

110. Calafat, 1993, p. 612.

111. Calafat, 1993, p. 614.

112. Calafat, 1993, p. 616.

113. Miquel Batllori (1996, p 478), califica a Joan Company de afamado hebraísta. El padre Company fue un exilado jesuita de Mallorca que se establece, como todos ellos, primero en Córcega y luego en las legaciones pontificias.

114. Calafat, 1993, p. 599. 
mallorquín de que se ha (sic) en las escuelas» ${ }^{115}$ para facilitar la práctica del Nebrija. A la sazón, tan solo Miquel Abrines se pronuncia a favor del gramático menorquín. Lo hace apelando a la doctrina de Port Royal vertida en el Nou mètode; a la vez que acomete contra el Sempere, echando mano de los viejos tópicos para tal propósito: «estando como está en idioma latino y medio intolerable para el logro del deseado fin» ${ }^{116}$.

El autor del Nou mètode, en el manifiesto de defensa que dirige al corregidor y a los regidores de la institución municipal, el 11 de mayo de 1764, se centra en dar respuesta a las críticas recibidas. Debemos entender que tuvo acceso a ellas no solo a través de los dictámenes, puesto que algunos son posteriores al alegato que él redacta, sino a partir de una supuesta reunión en el convento de los carmelitas: «He considerado con reflexión las objeciones que se hicieron a mi nuevo método en la Celda Prioral del Carmen»"17, dirá. Además, el franciscano Llorenç Company deja constancia en su escrito de cómo respondió Portella en aquel acto: «Allí en el Convento de los Muy Reverendos Padres Carmelitas, dijo, el que se llama su autor, que él no era autor; si que únicamente lo había sacado de otros métodos que eran indivisiblemente lo mismo» ${ }^{118}$. El hecho de que Portella elaborase su defensa a partir de lo expuesto en la celda del convento carmelita, pudiera explicar por qué en su alegato no se hace referencia a la cuestión de la lengua vernácula, motivo de polémica en los informes, y se concentre tan solo en rebatir cuestiones pedagógicas, arremetiendo contra sus obras rivales, escritas por Sempere y Nebrija:

En la gramática de Nebrija, que alguno de los examinadores propuso, tendríamos casi el mismo trabajo que con el Semperio: está en latín y, lo que peor es, casi todo en verso [...]. Los verbos están muy a lo largo, de suerte que un muchacho para hacerse bien capaz de ellos necesita aún más tiempo que con el Semperio, por faltar dos tratados muy esenciales para inteligencia y facilidad de ellos: el uno es el conocimiento de los verbos y el otro el de la formación ${ }^{119}$.

Sin duda, Antoni Portella litigaba en un contexto sociopolítico adverso que reducía su capacidad de alianzas, menoscabada por su origen ilustrado menorquín. Todo hace sospechar que la Comisión fue un puro trámite y los informes, una mera cuestión formal. Puede que no sea casualidad que el último en dictaminar fuera el padre carmelita, el 19 de mayo del 1764, autor en 1768, por encargo municipal, del Nebrija adaptado a los jóvenes mallorquines y arreglado a la Real Cédula.

\section{CONCLUSIÓN}

Antoni Portella presenta su obra en una Mallorca regida por los dictados borbónicos de imposición lingüística. Será a través de la enseñanza del latín que los

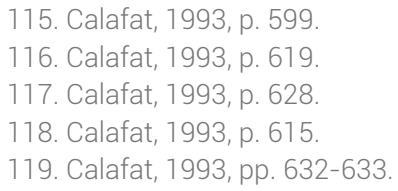


idiomas vernáculos se convertirán en materia de estudio por sí mismos e incluso, como ocurre en el caso que presentamos, instrumento de castellanización. Así lo pone de manifiesto el afán de algunos expertos de la Comisión, que juzgan el Nou mètode, por redactar, versionar y preparar libros de gramática en castellano a partir de los grandes maestros, Nebrija y Sempere; otorgando la institución municipal prioridad al primero por ser el que se ajusta a los dictados del Consejo de Castilla.

La polémica que suscita el método de Antoni Portella en la isla mallorquina sitúa a sus gramáticas y a sus gramáticos en el contexto del debate europeo en donde el tópico de explicar las bondades de los métodos escogidos atribuyéndoles las cualidades de la facilidad, la comprensión y la sencillez, se confronta con la oscuridad e inutilidad de las gramáticas a batir. De esta manera, el menorquín afea la gramática de Sempere y la de Nebrija; así como los defensores de imponer a Nebrija en Mallorca arremeterán contra la obra de Sempere o el Nou mètode.

Aunque su gramática se rija, con mayor o menor acierto, por las doctrinas pedagógicas reformadoras de la Europa de la llustración, los doctores escogidos por el Ayuntamiento de Palma, por ejercer en los centros principales de la Isla, no van a reconocerle mérito alguno ni valor, puesto que, de hacerlo, representaría aumentar la competencia en un mercado limitado; no sin descartar el hecho de que tales expertos consideraran a Portella poco menos que un intruso.

La situación política imperante era distinta en las dos islas, pese a su proximidad geográfica: en una, en Menorca, la lengua catalana tenía el uso de una lengua nacional plena; en la otra, en Mallorca, el nuevo orden borbónico propugnaba su rechazo en la enseñanza, en aras de la sustitución por el castellano. Estas realidades explican, en buena medida, el fracaso a que estaban abocadas las pretensiones del autor, que moriría un año después en Mallorca.

\section{BIBLIOGRAFÍA}

Arnauld, Antoine y Claude Lancelot, Grammaire générale et raisonnée contenant les fondemens de l'art de parler, expliqués d'une manière claire et naturelle, Paris, Pierre le Petit, 1660.

Badia, Antoni M., «La impronta renacentista en las letras catalanas. Latín y romance en los siglos XV y XVI», Revista de lenguas y Literaturas Catalana, Gallega y Vasca, 4, 1995, pp. 165-180.

Basols de Climent, Mariano, «Nebrija en Cataluña», Emérita, 13, 1945, pp. 49-64.

Batllori, Miquel, A través de la historia i la cultura, Barcelona, Publicacions de l'Abadia de Montserrat, 1979.

Batllori, Miquel, La cultura hispano-italiana de los jesuitas expulsos, Madrid, Gredos, 1996.

Bover, Joaquim M., Biblioteca de escritores baleares (la Ciutat de Mallorca, 1868), vols. I-II, Barcelona, Curial, documents de cultura-facsímil, 1975. 
Boyer, Henri, «La Revolució francesa a la recerca de l'unilingüisme», en La invención de les Ilengües nacionals, ed. Francesc Feliu y Cristina Juher, Barcelona, Quaderns Crema, 1992, pp. 103-121.

Breva-Claramonte, Manuel, La didáctica de las lenguas en el Renacimiento (Juan Luis Vives y Pedro Simón Abril. Con selección de textos), Bilbao, Universidad de Deusto, 1994.

Calafat, Rosa, Llengua i repressió a la Mallorca del segle XVIII, tesis doctoral parcialmente inédita, 1993.

Calafat, Rosa, Sabotatge a la llengua catalana, Palma, Lleonard Muntaner, 1999.

Calvo, Vicente, «Apuntes sobre el léxico romance en las gramáticas latinas al uso en la escuela valenciana del XV», en La Universitat de València i l'Humanisme: «Studia Humanitatis» i renovació cultural a Europa i al Nou Món, ed. Ferran Grau, Xavier Gómez, Jordi Pérez y José M. Estellés. Valencia, Departament de Filologia Clàssica, Universitat de València, 2003, pp. 239-254.

Casanova, Pascale, La República mundial de las Letras, Barcelona, Anagrama, 2001.

Certeau de, Michel, Dominique Julia y Jacques Revel, Una politique de la langue. La Révolution française et les patois, París, Gallimard, 1975.

Comas, Antoni, Les excel/lències de la llengua catalana, Barcelona, Dalmau, 1967.

Espino Martín, Javier, «Enseñanza del latín e historia de las ideas, la Revolución de Port-royal y su repercusión en Francia y España durante el siglo XVIII», Minerva, 23, 2010, pp. 261-284.

Ferrando, Antoni y Miquel Nicolás, Història de la llengua catalana, Barcelona, UOC, 2011.

Ferté, Patrick, «Catalans et lumières: les étudiants de Minorque a l'Université d'Avignon au XVIIIè siècle», Provence historique, 192, 1998, pp. 179-203.

González de la Calle, Pedro Urbano, «Latín y romance. Contribución al estudio de la vida docente espanyola en el siglo XVl», Varia, Madrid, 1916, pp. 211-299.

Gran Enciclopèdia Catalana. Disponible en línea: <http://www.enciclopedia.cat/ enciclop\%C3\%A8dies/cerca?s.q=Ilemos\%C3\%AD\&s.book=gec\&searchgo=Cerca\#.VH9Zn8lg-u4> [03/09/2017].

Ijsewijn, Jozef, «Scrittori latini a Roma dal Barroco al Neoclassicismo», en Humanisme i literatura neollatina, ed. Josep Lluís Barona, València, Universitat de València, 1996, pp. 191-209.

Lancelot, Claude, Nouvelle méthode pour apprendre facilement et en peu de temps la langue latine, contennant les rudiments et les regles del genres, des Declinaisons, des Preterits, dela Syntaxe, et de la Quantité, París, Antoine Vitre, 1650. 
Lázaro Carreter, Fernando, Las ideas lingüísticas en España durante el siglo XVIII, Barcelona, Crítica, 1985.

Marcet, Pere, Història de la llengua catalana, Barcelona, Teide, 1987, 2 vols.

Marcet, Pere y Joan Solà, Història de la lingüística catalana 1775-1900, volum I i II, Girona, Universitat de Girona/Eumo, 1998.

Marcos Marín, Francisco, Introducción a la Lingüística: Historia y Modelos, Madrid, Síntesis, 1994.

Martín, Miguel y Charo Nevado, «La enseñanza de lenguas extranjeras en los siglos XVI-XVIII. El caso del español», Ogigia, revista electrónica de estudios hispánicos, 5, 2009, pp. 5-18.

Murillo, Andreu, «La crisi educativa arran de la devolució definitiva de Manorca a la corona d'Espanya», Educació i Cultura, 5-6, 1982, pp. 71-81.

Nadal, Josep M., «Normativa i Història de la Llengua», en La invención de les Ilengües nacionals, ed. Francesc Feliu y Cristina Juher, Barcelona, Quaderns Crema, 1992, pp. 13-37.

Nadal, Josep M., Llengua escrita i llengua nacional. Barcelona, Quaderns Crema, 1992.

Oléo, Rafael, Historia de la isla de Menorca, Mahón, tip. de D. S. Fábregues, 1874.

Paredes, Maria (ed.), Antoni Febrer i Cardona (Maó, 1761-1841), Barcelona, Institut d'Estudis Catalans, Biblioteca Filològica, 2005.

Pomar, Jaume, Assaig històric sobre el desenvolupament de la instrucció pública a Mallorca, Palma de Mallorca, Conselleria de cultura, Educació i Esports, Govern Balear, 1990.

Ponce de Léon, Rogelio, «La difusión de las artes gramaticales latino-portuguesas en España (siglos XVI-XVII)», Península, Revista de Estudos Ibéricos, 0, 2003, pp. 119-145.

Portella, Antoni, Nou mètode per aprendre la llengua llatina. Primera part dels Rudiments, Maó, en casa de Joseph Payen, 1762.

Rafanell, August, La llengua silenciada, Barcelona, Empúries, 1999.

Reixac, Baldiri, Instruccions per a l'ensenyança de minyons, tom II, ed. Salomó Marqués y Albert Rossich, Girona, Colllegi Universitari de Girona, 1981.

Robins, Robert H., Breve historia de la lingüística, Madrid, Cátedra, 2000.

Rubió i Balaguer, Jordi, Història de la Literatura Catalana, 1, Montserrat, 1984.

Sánchez Salor, Eustaquio, « ¿Qué arte de gramática enseñar en el siglo XVI? El caso de Valencia», en La Universitat de València i I'Humanisme: Studia Humanitatis i renovació cultural a Europa i al Nou Món, València, Departament de Filologia Clàssica, Universitat de València, 2003, pp. 193-218. 
Sánchez Salor, Eustaquio, «Gregorio Mayáns y la Gramática latina», Studia Philologica Valentina, 14, 11, 2012, pp. 447-473.

Serra Ràfols, Elies, «La Introducció del castellà com a llengua d'ensenyament», Estudis romànics, 12, 1970, pp. 19-28.

Solà, Joan, «El llatí a l'ensenyament medieval», Randa, 9, 1979, pp. 65-71.

Soldevila, Ferran, El compromís de Casp, Barcelona, Rafael Dalmau, 1994.

Teorodo Peris, Josep, Vida i mort de la llengua Ilatina. Una polèmica lingüística al segle XVIII, València, Universitat de València, 2004.

Trudeau Danielle, Les inventeurs du bon usage (1529-1647), París, Les Éditions de Minuit, 1992. 
